\author{
Jean-Michel Jeannin
}

Einleitung

Spathodea campanulata (andere Namen: African Tulip Tree, Flame Tree, afrikanischer Tulpenbaum, Tulipier du Gabon usw.) ist ein kräftiger Baum aus der Familie der Bignoniaceae. Er erreicht eine Höhe von 15-30 m; sein Stamm kann bis $80 \mathrm{~cm}$ dick werden (Abb. 1). Die Rinde ist grau. Die Laubblätter sind unpaarig gefiedert, auf der Unterseite kräftig behaart oder glatt. Das auffälligste Merkmal sind die grossen, glockenförmigen, kräftig orange bis scharlachroten Blüten. Die Blüten sind in kreisförmigen Gruppen angeordnet, in deren Zentrum die zahlreichen braunen Blütenknospen angeordnet sind (Abb. 2). Der Geruch der Blüten und der Knospen wird als unangenehm beschrieben. Die Früchte von S. campanulata sind spindelförmige, aufrecht stehende, braun-schwarze Kapseln, welche die membranartig geflügelten Samen enthalten. Der Baum ist im tropischen Afrika heimisch [1]. Er wird heute überall angepflanzt, wo es das Klima erlaubt [2].

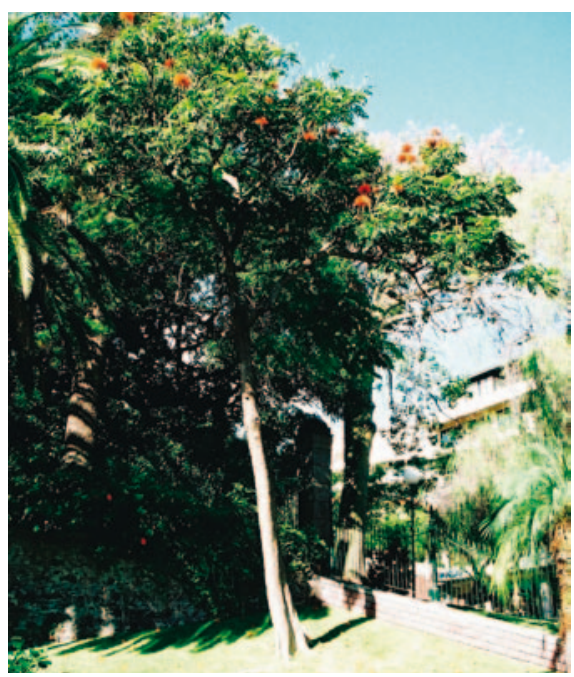

Abb. 1. S. campanulata. Habitus. Madeira 2009.

\title{
Exotische Heilpflanzen (2)
}

\author{
Spathodea campanulata P. Beauvois (Bignoniaceae)
}

\section{Verwendung als Heilpflanze}

S. campanulata wird in der traditionellen afrikanischen Medizin sehr vielfältig verwendet. Die Attjé (Elfenbeinküste) stellen eine Paste aus den Blättern von S. campanulata und von anderen Pflanzen sowie Kaolin her. Die mit Wasser verrührte Paste wird als Getränk zur Behandlung des Spitzbuckels der Wirbelsäule verabreicht. In mehreren Regionen (Südkamerun, bei den Bulu, in Benin) werden Zubereitungen der Rinde (Pulver, wässriger Extrakt) zur Behandlung von Wunden und Narben eingesetzt. In Togo wird ein Dekokt der Stammrinde peroral zur Behandlung der unregelmässigen Menstruation und zur Waschung von schlecht heilenden Wunden appliziert. In Nigeria behandelt man Ulzera, Ödeme und Hautkrankheiten mit der Rinde, den Blättern und den Blüten. Mit dem Blätterdekokt behandelt man Harnleiter-Entzündungen, mit dem Dekokt der Rinde Dysenterie und Diarrhö. In Ober-Shanga (Kongo) trinken die

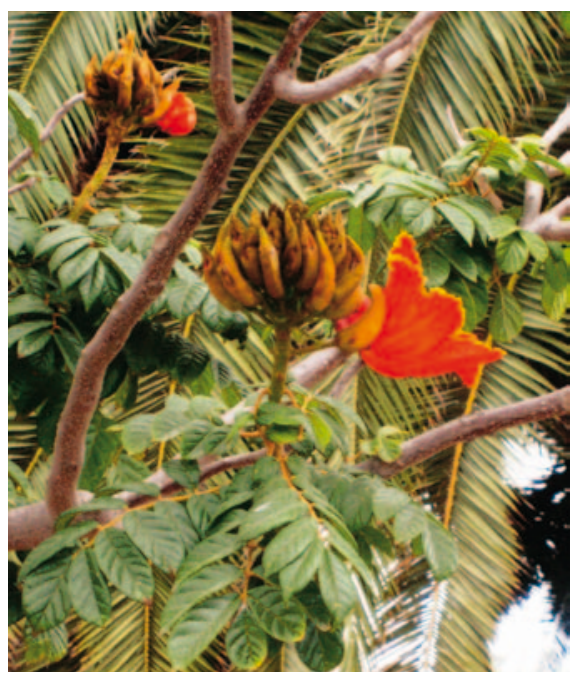

Abb. 2. S. campanulata. Blüten und Blütenknospen. Teneriffa 2008.
Männer das Rindendekokt zur Behandlung von Skrotalhernien und syphilitischen Wunden. In Zaïre werden Asthma-kranke Kinder mit einem Rindenmazerat behandelt. In Ruanda wird das Stammrindendekokt zur Behandlung des Diabetes mellitus eingesetzt. In Burundi wird bei Seitenstechen die Asche der Rinde gegessen [1].

\section{Pharmakologie und Toxikologie}

In den Blättern konnten je nach Herkunft Alkoloide (Nigeria), Tannine (Ägypten) und Kaffeesäure sowie Quercetin (Indien) identifiziert werden. Es wurde auch der neue Sterolalkohol Spathodol gefunden. In der Rinde wurden Tannine, Verminosid, Vanillinsäure, Ferulasäure und Atranorin gefunden. Die Blüten enthalten Anthocyanine, die Früchte Saponine, Tannine, Polyphenole und Glykoside. Die Pflanze wird von den afrikanischen Heilkundigen als toxisch betrachtet; ein exakter Nachweis dieser Toxizität fehlt bisher. Aus neueren Untersuchungen: Quercetin hemmt in vitro Plasmodium falciparum sowie menschliche maligne Zellen des Intestinaltrakts. Extrakte der Stammrinde und der Früchte töten die Schnecke Bulinus africanus. Ein wässriger Extrakt aus den Früchten war um ein Mehrfaches wirksamer als ein wässriger Extrakt aus der Rinde. Ein methanolischer Rindenextrakt war am wirksamsten [1].

\section{Literatur}

1 Neuwinger HD: Afrikanische Arzneipflanzen und Jagdgifte, ed 2. Stuttgart, Wissenschaftliche Verlagsgesellschaft, 1998.

2 Lipps S: Was hier alles wächst!, ed 3. Duisburg, Oliver Breda, 2008. (c) 2010 S. Karger GmbH, Freiburg
Dipl. med. biol. Jean-Michel Jeannin Holeestrasse 43, 4054 Basel, Schweiz Tel. +41 61-4215991, Fax - 4230313 jmjeannin@dataworks.ch 